\title{
The Asia Academy of Management
}

\author{
Chung-Ming Lau \\ Department of Management, Chinese University of Hong Kong, Hong Kong \\ E-mail:cmlau@baf.msmail.cuhk.edu.hk, Website: www.baf.cuhk.edu.hk/asia-aom
}

In the interests of furthering research, education and the dissemination of knowledge relating to Asian management issues, the Asia Academy of Management was founded in 1998, at an inaugural conference in Hong Kong, hosted by the Chinese University of Hong Kong.

Affiliated to the Academy of Management, the aim was to encourage contextualized management research with relevance to Asia. It is intended to develop a cutting-edge position in the fields of management theory, research and education, expanding from its Asian focus to global relevance in its research and study. It is open to all persons, academic or managerial, with an interest in Asian management issues.

The theme of the Inaugural Conference, 'Does Asian Management Matter: Regional Relevance with Global Impact', attracted over 150 participants and signified the interest of a variety of scholars in the uniquely Asian management practices that have emerged from the cultural roots of Asian societies and the economic, social, political and technological forces that have shaped them. Asian management has had significant impact on management affairs all over the world, and among the keynote presenters on this theme were Professor John Child, Professor Michael Hitt, Professor Geert Hofstede, Professor KinChok Mun and Professor Chow-Hou Wee. Selected papers from the conference, addressing Asian culture and management, the globalization of Asian firms, strategic management in Asia, and human resource management in the region, were published in Asian Management Matters: Regional Relevance and Global Impact, (Imperial College Press; distributed by World Scientific Publishing).

The National University of Singapore hosted the Second Conference in December 2000. This time over 200 participants from all over the world discussed topics around a theme of 'Managing in Asia: Challenges and Opportunities in the New Millennium', and highly perceptive insights into Asian management were aired. The Third Conference, in December 2002, will move to Bangkok, Thailand, as the guest of Chulalongkorn University; the theme will be 'Innovating Asian Management in the 21st Century'.

The Asia Academy pursued an open membership policy for its first years, gathering over 800 members, and on January 1, 2002, the Asia Pacific Journal 
of Management became the Academy's official journal. In order to cover the resultant costs of the journal and improve the Academy's services to its members, membership fees have now been instituted. Full members will, as in other academic organizations, receive a copy of the journal as well as other benefits.

The Asia Pacific Journal of Management has already been in publication under the aegis of the School of Business at the National University of Singapore for 18 years and has built up a solid reputation worldwide amongst those interested in Asian management studies. Through its relationship with the Academy, it is expected that the Journal will become an even more important vehicle for serious and rigorous management studies relevant to Asia. This collaboration represents a major step forward in the advancement of Asian management research.

The Asia Academy has close links not just with the Academy of Management, but also with other regional affiliates, including the Iberoamerican Academy and the Australian and New Zealand Academy. Professional development workshops are regularly organized at the Academy of Management Annual Meetings. Through a variety of scholarly activities and relationships, including the journal, conferences and workshops, the Asia Academy stands ready to achieve global recognition and take management research to new frontiers. 